The measurement of absorption in tinted glasses

This content has been downloaded from IOPscience. Please scroll down to see the full text. 1904 Trans. Opt. Soc. 643

(http://iopscience.iop.org/1475-4878/6/1/304)

View the table of contents for this issue, or go to the journal homepage for more

Download details:

IP Address: 130.179.16.201

This content was downloaded on 07/09/2015 at 17:29

Please note that terms and conditions apply. 


\section{THE MEASUREMENT OF ABSORPTION IN TINTED}

\section{GLASSES.}

Paper bx Mr. L. W. Phillips, Student Member.

Read before the Optrcal Society, February 19th, 1906.

The subject before you this evening has been, I believe, to many of you a source of interest, and also great difficulty for some time past. Those engaged in spectacle work, when using tinted glasses, have been unable to speak with certainty as to the amount of light absorbed in, or transmitted through these glasses, resource having to be taken to guess-work, the accuracy and facility of which depended upon experience. This existing need for a method of measuring absorption in tinted glasses was further emphasised by the report of the Optical Standard Committee, which was presented to you on the 21 st of last April. Among the other excellent recommendations embodied in that report was one referring to coloured glasses, which read as follows:-

"That the following is a suitable series of standards for neutral tinted and coloured glasses, viz.:-

No. 1 transmitting $80 \%$ of incident white light.

\begin{tabular}{|c|c|c|c|c|c|}
\hline ", 2 & , & $65 \%$ & "' & ", & $"$ \\
\hline, 3 & " & $50 \%$ & " & ", & ", \\
\hline 4 & " & $40 \%$ & ", & ," & ", \\
\hline 5 & "' & $30 \%$ & ", & $"$ & "' \\
\hline 6 & $"$ & $20 \%$ & $"$ & ", & ", \\
\hline 7 & ", & $10 \%$ & $"$ & $"$ & " \\
\hline, 8 & " & $5 \%$ & " & ", & " \\
\hline 9 & $"$ & $2.5 \%$ & ", & $\because$ & " \\
\hline, 10 & و & $1.25 \%$ & ", & $"$ & " \\
\hline
\end{tabular}

With this recommendation all Opticians, I think, are in agreement, realising the need for such standardisation in their work. Those wishing to carry out the suggestion, however, found themselves willing but unable to do so, for they were met with the new problem of where to obtain a standard set of glasses, or if they wished to make their own tests, how to proceed. It is for the pur- 
pose of trying to help you in this matter that I am bringing this paper before you for your consideration this evening.

The problem, at first sight, appears quite simple, as one has only to measure the amount of light received on a screen from a given source, and then interposing the tinted glass between the source of light and the screen, again measure the light received on the latter. The first result, minus the second, will give the amount of absorption.

As the measurement is photometric, perhaps it will be well at this point to call to your mind the general elementary principles of photometry. The method of measurement is as shown in fig. 1 , and will be seen that the apparatus consists of two sources of light, the relative intensities of which are to be determined, and a

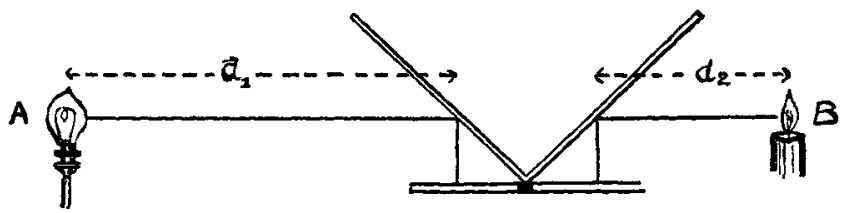

FIG. 1 .

screen which is moved into such a position between the two lights that it is equally illuminated by both. If the distances between the screen and the two sources of light $\mathrm{A}$ and $\mathrm{B}$ are denoted by $d$, and $d_{2}$, respectively, then

$$
\frac{\mathrm{A}}{\mathrm{B}}=\left(\frac{d_{1}}{d_{2}}\right)^{2}
$$

When dealing with white lights, or lights of the same colour, the matter is very simple, but when the colours are different the matter becomes difficult. This difficulty is very similar to that experienced in trying to compare the loudness of two sounds differing in quality, such as that produced by shouting and the shrieking of a railway engine whistle. To make this colour difficulty clear to you I will have thrown on the screen two discs of white light, and you see it is very easy to tell that they are equally bright. If $I$ now interpose two different coloured glasses in front of the apertures through which 
the light is passing, you will notice that now there is diffculty in judging when the dises are of equal brightness.

The National Physical Laboratory Method.-The measurement of absorption at the National Physical Laboratory is carried out by means of spectrophotometry; the instrument used being a modified form of the König spectrophotometer.

In this piece of apparatus light from a given source passes through two slits, one of which is covered by the glass whose absorption is to be determined. These two beams of light thus formed pass through the same train of prisms and each forms a spectrum; the two spectra being one above the other. These spectra are then polarised at right angles to one ancther, and any particular portion viewed through a Nicol analyser. This Nicol is then turned until the intensity of the two similar portions of the spectra are equal, and when this is the case if $\theta$ be the angle of inclination of the principal plane of the Nicol with the horizon and $I_{1}$ and $I_{2}$, the intensity of the two beams then $\frac{I_{1}}{I_{2}}=\tan ^{2} \theta$.

If $\mathrm{I}_{2}$ represents the intensity of the light passing through the glass being tested, then the percentage of $100 I_{1}$

light transmitted $=\frac{10 I_{1}}{\tan ^{2} \theta}$, and the absorption $=I_{1}$ $\frac{I_{1}}{\tan ^{2} \theta}=\frac{I_{1} \tan ^{2} \theta-I_{1}}{\tan ^{2} \theta}$

A full description of the apparatus, with illustration and explanation of its use, is found in the paper by our President, Dr. Glazebrook, entitled, "The Optical Society and the National Physical Laboratory," and is printer in the "Transactions" for the year 1903-04. Although this is a very good method, it is only suitable for a large laboratory, as the instrument is rather costly, and as each part of the spectrum is viewed separately, the calculations for absorption are a little difficult to work out.

The necessity, therefore, was for an instrument which was simple in its construction and use, so that it should be not only inexpensive, but accurate in working, and if possible allow the measurement to be quickly carried 
out. As the ordinary type of photometric screen was not of any use for the measurement of absorption in coloured glasses owing to the difficulty in making comparison, it was needful that some different method should be employed. In 1893 Professor O. N. Rood suggested the method of Flicker as a means of eliminating the colour difficulty, and it is this method, as applied in the Simmance-Abady Photometer, that I wish to speals about this evening.

Principle of the Flicker Photometer.-If we have two sources of light illuminating two different surfaces which are brought alternately into view at a suitable periodicity, when unequally illuminated, a throbbing or flicker effect will be noticed. According to one theory
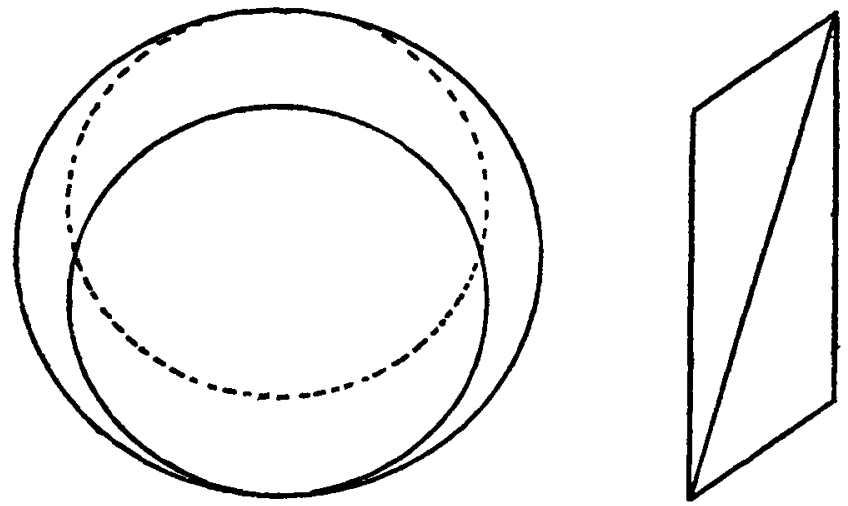

FIG. 2.

this effect is caused by the pupil of the eye failing to keep in time with the rapid change of intensity of illumination shown by the two screens. When, however, the relative positions of screens and lights are such that the surfaces viewed are equally illuminated, the intensity of the illumination seen being unchanged this flicker will disappear, and one sees, as it were, one unmoving illuminated surface. The reason for the colour difficulty being eliminated is, that the visual senses of lightness and colour are different, the former sense being much keener and quicker in action than the latter.

This view is supported by the German Optologist (Professor Hering), who states that he believes the physio- 
logical senses of perception of colour and brightness to be different-the former being able to present without the latter. In a darkened room, across which a bright light flashed momentarily, although it would be possible to judge somewhat of the brightness of the beam, it would be impossible to say anything definitely as to its colour.

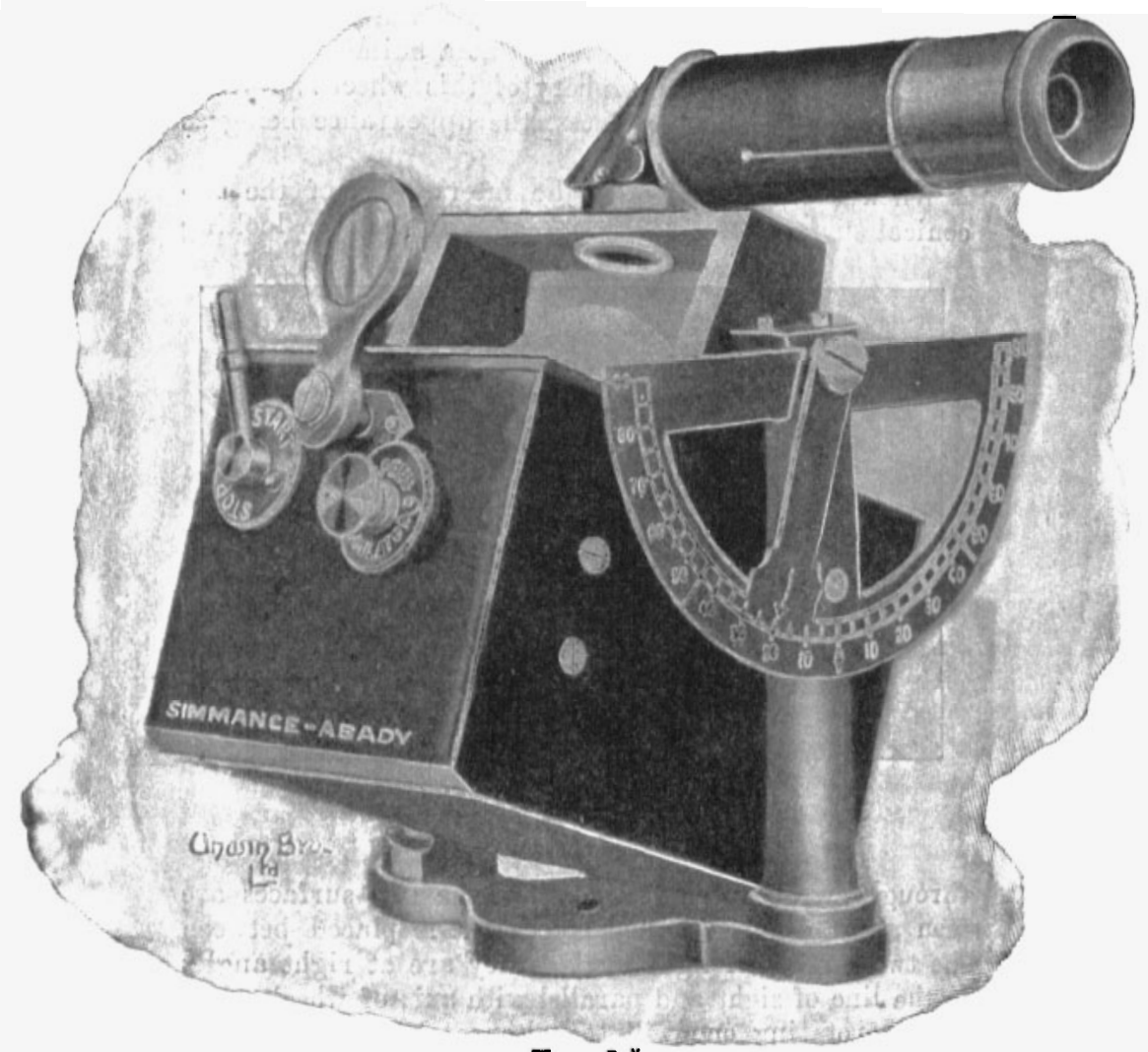

Fig. 3.*

The theory is very interesting, and I hope that those present this evening who have interested themselves in colour measurement will give their opinion on this point.

* The type of Flicker Box shown in fig. 3 can also be used for angular as well as horizontal measurements 
In the Flicker Photometer, owing to the fact that the rate of bringing first one screen and then the other into view is so great, the eye has not time to take notice of the colour of the illuminated screen, but is affected only by its brightness. In the Simmance-Abady type of Flicker photometer, as shown to you this evening, it will be seen that light from the two sources is received upon $\mathfrak{a}$ wheel made of pure white material, which, by means of a clockwork motor, is revolved at a suitable and controllable speed. The periphery of this wheel is formed by two equal conical surfaces, the appearance being as shown in fig. 2.

When the wheel revolves the intersection of the two conical surfaces crosses the line of sight, and on looking

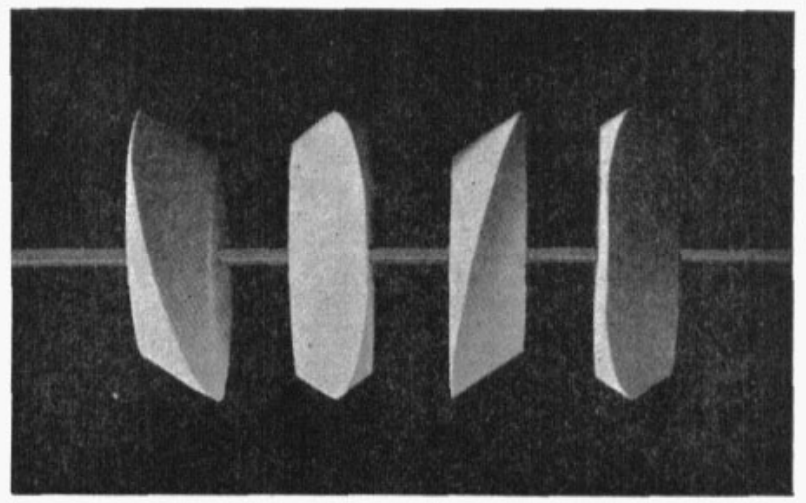

FIG. 4.

through an eye-piece at the wheel the two surfaces are seen alternately. If the photometer is placed between the two sources of light so that they are at right angles to the line of sight and parallel with axis of wheel, when this is rotating one will see alternately the effect produced by each light. Fig. 3 shows an external view of the Simmance-Abady Photometer, while fig. 4 shows clearly the appearance of the wheel in its four positions when illuminated unequally on the opposite sides.

Reliance to be Placed in use of Fuicker PhotoMETER.-If light from two coloured sources (say red and green) is received upon the two faces of a right- 
angled wedge, balance may be obtained to a certain degree of satisfaction, but now, if the lights be moved to either double or half the previous distances from the wedge, the illumination on the two faces will no longer be found to balance. This Purkinje phenomenon, as it is known, is purely a colour effect, and, happily, does not affect the Flicker Photometer, for if it did one would have to introduce a factor dealing with the distance between the lights and the screen.

The Purkinje phenomenon is due to the fact that the retinal sense of brightness does not increase at the same rate for different colours, and is a great argument to show the necessity of entirely eliminating colour in any photometric measurement. Tests that were carried out by two gentlemen connected with the Ophthalmic

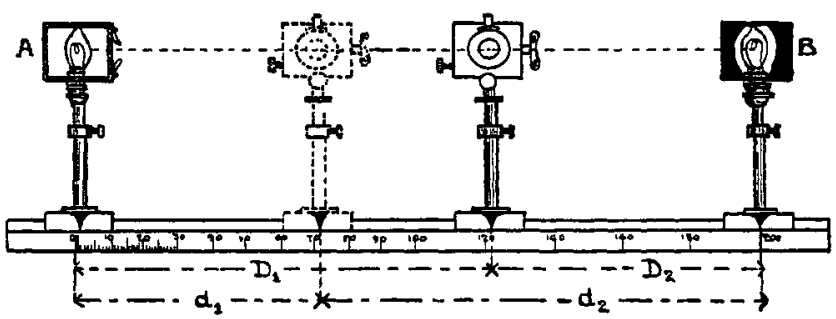

FIG. 5.

Hospital went to show that any visual defect in the eyes of the observer did not make any difference in reading. Readings were taken by observers who were respectively astigmatic, and colour blind, and another whose pupil was dilated by atropine specially for the experiment. The readings obtained by these observers were found to coincide not only when the colours were the same, but when they widely differed.

Absorption Measurement.-In making the absorption measurement a bench of about 2 metres in length should be chosen, and this should be divided into millimetre divisions. If possible, a substantial type of bench should be used, but if not convenient any ordinary wooden optical bench will do. At the two ends of this bench sources of light should be arranged, and in front of these are put screens having in their centre an aperture alout 
three-quarters of an inch square, or, better still, if electric lamps are used they should be enclosed in a blackened box with an aperture in the front. Between these screens the photometer is put and care should be taken to arrange lamps, screens, and photometer in a straight line. On the screens a clip should be arranged for holding a spectacle glass in front of the aperture, but if not convenient at the time an elastic band will do almost as well. When the apparatus is ready for malking test run the Flicker wheel at a suitable speed and more flicker box into the position where flicker disappears. If distances from lights $A$ and $B$ to screen are $D_{1}$ and $D_{2}$, respectively, then $\frac{A}{B}=\left(\frac{D_{1}}{D_{2}}\right)^{2}$

If a coloured glass is now put in front of aperture in screen at $A$, and flicker is found to disappear at a position where readings are now $d_{1}$ and $d_{2}$;

Then if light passing through glass be $\mathrm{A}^{1}$ then

$$
\frac{\mathrm{A}^{1}}{\mathrm{~B}}=\left(\frac{d_{1}}{d_{2}}\right)^{2} \text { therefore the ratio of } \frac{\mathrm{A}^{1}}{\mathrm{~A}}=\left(\frac{d_{1}}{d_{2}} \times \frac{\mathrm{D}_{2}}{\mathrm{D}_{1}}\right)^{2}
$$

and the percentage of light transmitted $=\left(\frac{d_{1}}{d_{2}} \times \frac{D_{2}}{D_{1}}\right)^{2} \times 100$ and the percentage of light absorbed will be given by the equation $100\left(1-\left\{\frac{d_{1}}{d_{2}} \times \frac{\mathrm{D}_{2}}{\mathrm{D}_{1}}\right\}^{2}\right)$

If the length of the bench is $\mathrm{L}$ cms., it can easily be seen that $\mathrm{D}_{2}=\mathrm{L}-\mathrm{D}_{1}$, and $d_{2}=\mathrm{L}-d_{1}$.

To make this clearer, let us take a numerical example. Supposing we have a bench $200 \mathrm{cms}$. in length and balance in the two cases is at $102 \mathrm{cms}$. and $150 \mathrm{cms}$., respectively. Then $\mathrm{D}_{2}$ and $d_{2}$ will be 98 and 50 , so that percentage of light transmitted by glass tested would equal $\left(\frac{102}{98} \times \frac{50}{150}\right)^{2} \times 100=\left(\frac{51}{141}\right)^{2}=13.08 \%$

If the lights are of equal intensity $D_{2}$ will be equal to $\mathrm{D}_{2}$, so that the percentage of light transmitted will equal 


$$
\left(\frac{d_{1}}{d_{2}}\right)^{2} \times 100=\left(\frac{d_{1}}{L-d_{1}}\right)^{2} \times 100
$$

Another method which simplifies the calculation is to have the light at $\mathbf{B}$ rigidly connected to the support of the photometer, so as to keep it a constant distance. If this is the case then $D_{2}$ and $d_{2}$ are equal, and percentage of light transmitted will be $\left(\frac{d_{1}}{\mathrm{D}_{1}}\right)^{2} \times 100$.

Reference to fig. 5 will make the matter clearer as to the different distances, and will also show the general arrangement of bench.

SOURCES OF LIGHT.--In ordinary photometry the great difficulty is to get some standard sources of light, but in absorption testing this trouble is not encountered, for the measurement is not an absolute measurement of candlepower but of the ratio between two sources of light, as will be seen by reference to calculations already given. One does not need a souree of light which can always produce a definite candle-power, but rather one which can be relied on to keep constant while the tests are carried out. Even this is not necessary if the readings with the white light are taken each time between the readings with the glasses inserted in front of aperture; but if the light is constant this is aroided, and, in consequence, a good deal of time saved. In a series of tests which I carried out, the figures for which are given at the end of the paper, Nernst lamps of the old type were used.

These I found to be troublesome, as they were constantly varying in intensity of light given, very sensitive to variation of voltage, and if switched off and then on again their intensity was found to be different. If a small 6-volt lamp is used and supplied with current from a small accumulator, the voltage being constant for some time, the light given will be more steady than with a lamp run off the mains. When gas ligliting is employed an Argand burner proves very satisfactory, as the small portion of centre of flame seen through aperture can be relied on for constancy. The same may be said of a burner used in conjunction with the Welsbach incandescent mantle. From the result of experiments I think the most satisfactory sources of light to use are either an Argand burner for gas, or a small glow lamp with 
straight filaments supplied with current from an accumulator.

Electric lighting is to be preferred owing to its great convenience and portability in enabling lights to be quickly shifted, and also because if used in a confined space one does not have the discomfiture of the atmosphere becoming very warm, as would be the case with gas.

Conditions for Sensitiveness.-Although to enable one to get sensitive results it is necessary to pay attention to several points, yet on the other hand there is nothing to deter an Optician from getting very satisfactory results with just the ordinary apparatus at his disposal.

In the first place, however, care should be taken to see that the bench is quite level, and that it is rigidly fixed. The runners on which the sources of light, sereen, and photometer are fixed should be preferably of the $V$ type, fitting without any possible shake on the central ridge of the photometer bench; a screw should also be provided to clamp them in any desired position. These supports should have, if possible, a racking mechanism to easily and accurately adjust their height. When all is ready care should be taken to see that the sources of light and photometer are in perfect alignment, otherwise it is impossible to get very good results.

It is also necessary for the flicker wheel to be kept very clean, for if it becomes dirty on either of the conical faces the flicker will not, of course, disappear. The sources of light should be capable of adjustment; if gas is used a governor being employed to carefully regulate supply, and if electric lighting an adjustable resistance should be connected in circuit. When using the photometer the speed of the wheel should be arranged for the best sensitiveness, and this is obtained by finding position one thinks balance is found and then slowing down until the speed is the lowest for which flicker will disappear. Below a certain speed the colour difficulty enters in, this minimum speed from my observation seeming to vary with the colour of the glass tested. If one finds it difficult to fix on any position of total disappearance the best method is to obtain an equal amount of flicker on both sides of where the point of disappearance should be, and then take mean reading. The most sensitive position of photometer screen is in centre of bench, therefore, 
when testing a glass which passes only a very small percentage of light it is often advisable to use an intermediate tint on the other side, that is, at $\mathbf{B}$, where white light would be in the ordinary method of use. This enables reading to be more near centre, and if, therefore, a small error is made it will not matter so much as if reading were at end of bench, as would have been the case if no intermediate tint had been used.

Readings should be taken as quickly as possible, consistent with accuracy, moving the photometer first in one direction and then in the other, coming back to the position where the flicker disappears. If one takes too long in settling at the position of balance the eye becomes fatigued, and cannot fix upon any definite position for disappearance. It is also better for two persons to be engaged in making observations, as this checks each reading, and at the same time gives the observer opportunity for resting the eye between the readings, thus aroiding fatigue.

Results Ortained by ORdiNary Mgans.-The hints given above are such as to be easily compiled with, and although we should do our best it does not lie within the scope of every Optician to have everything most suitable for carrying out these measurements. No special room is necessary for making the measurements, as it will be quite satisfactory if a part of the ordinary laboratory or sight testing room with blackened walls, is divided off by means of a curtain. Even if a good bench cannot be obtained the results given below will show that satisfactory measurements can be made. The bench used in the tests taken was not very stable, and was divided into two centimetre divisions only.

Readings were taken by two observers and found to check out satisfactorily. The figures given were those obtained on several different occasions.

The results given above, I hope, will encourage those who have but little apparatus and convenience at their disposal, and show that there is good reason for them to do work of this description, even with limited apparatus and opportunities. The difference between the readings is not very much, but, with a good type of bench and sensitive arrangements, reading's taken at any time will be found to be in perfect agreement. 


\begin{tabular}{|c|c|c|c|c|c|c|c|}
\hline \multicolumn{2}{|c|}{ Colour \& No. } & \multicolumn{2}{|c|}{\begin{tabular}{|c|c|} 
Test 1 & Test 2 \\
$\%$ light & $\%$ light \\
passed. & passed.
\end{tabular}} & \multicolumn{2}{|c|}{ Colour \& No. } & Test 1 & Test 2 \\
\hline Blue & $\begin{array}{r}1 \\
2 \\
3 \\
4 \\
5 \\
6 \\
7 \\
8 \\
9 \\
10 \\
11 \\
12 \\
13 \\
14 \\
15\end{array}$ & $\begin{array}{l}18.4 \\
41.3 \\
18.4 \\
22.1 \\
16.3 \\
16.65 \\
15.5 \\
4.1 \\
2.46 \\
43.8 \\
53.8 \\
57 \\
78.6 \\
53.5 \\
81.7\end{array}$ & $\begin{array}{l}19.25 \\
43.2 \\
18.2 \\
22.8 \\
17.1 \\
16.5 \\
16.5 \\
4.15 \\
2.39 \\
43.45 \\
53.9 \\
57 \\
78.25 \\
52.5 \\
81.8\end{array}$ & Smoke & $\begin{array}{r}1 \\
2 \\
3 \\
4 \\
5 \\
6 \\
7 \\
8 \\
9 \\
10 \\
11 \\
12 \\
13 \\
14 \\
15\end{array}$ & $\begin{array}{l}42.1 \\
18.4 \\
22.4 \\
54.5 \\
1335 \\
46.5 \\
416 \\
189 \\
26.7 \\
39.8 \\
61.5 \\
72.2 \\
39.8 \\
7.0 \\
63\end{array}$ & $\begin{array}{c}42.2 \\
182 \\
22.3 \\
53.2 \\
12.9 \\
47.5 \\
42.7 \\
18.8 \\
27.8 \\
39.5 \\
62 \\
72.8 \\
39.5 \\
7.1 \\
6.25\end{array}$ \\
\hline Green & $\begin{array}{r}1 \\
2 \\
3 \\
4 \\
5 \\
6 \\
7 \\
8 \\
9 \\
10\end{array}$ & $\begin{array}{l}78.5 \\
12.2 \\
15.7 \\
19.6 \\
15.6 \\
15.1 \\
24.3 \\
15.75 \\
29.6 \\
32.4\end{array}$ & $\begin{array}{l}78.6 \\
13.1 \\
16.5 \\
20.3 \\
15.9 \\
17.1 \\
26.3 \\
15.8 \\
29.8 \\
32.8\end{array}$ & Green & $\begin{array}{l}11 \\
12 \\
13 \\
14 \\
15 \\
16 \\
17 \\
18\end{array}$ & $\begin{array}{l}15.7 \\
136 \\
21.3 \\
26.5 \\
12.25 \\
10.0 \\
13.1 \\
19.1\end{array}$ & $\begin{array}{l}15.9 \\
184 \\
225 \\
25.3 \\
119 \\
11.6 \\
13.5 \\
20.6\end{array}$ \\
\hline
\end{tabular}

For those, however, who simply require a standard set of tints, and do not wish to carry out any measurements themselves, it would be well if some Institution such as the National Physical Laboratory were to issue such sets so that the recommendations of the Optical Standards Sub-Committee could be carried out.

In conclusion, I should like to heartily thank Messrs. Alex. Wright and Company, the manufacturers of the Flicker Photometer, who have so kindly arranged for demonstrations this evening. I am also indebted to Messrs. Raphael, Wheway, and Redfern, for their kindness in lending a set of tinted glasses for experimental purposes. 


\section{Discussion.}

Mr. DIXEr said he could have wished that he had had more opportunity of preparıng a few remarks that might have been useful in connection with the subject, as there were many things he would like to have said about it. The scale of percentages that was given at the beginning of the paper, which could, no doubt, be approximated in the tints that were used for ophthalmic work, would be useful; the methods in vogue at present were not at all satisfactory. They were not scientific; being based in the old-fashioned way upon an arbitrary scale of numbers without any definite reference to the amount of light absorbed. He might say that rigid accuracy was not demanded in ophthalmic work-an approximation was all that one need ever reasonably aim at. The chief object of calibrating the tints was more for the purpose of maling a prescription intelligible-that a doctor or a prescriber should convey approximately the idea of the depth of tint he wants to the man who is to make the spectacles, rather than that he himself should know the exact amount of light transmitted to his patient's eye. That must be so, because, as a matter of fact, the amount of light that is transmitted is regulated, not by the percentage of light transmitted by the glass, but by several physiological and other conditions of the sight, as for instance, the automatically acting diaphragm that they all had in front of their eyes, the iris. A certain effect of putting a dark lens in front of one s eye was to distend the iris. Then again, if Mr. Phillips was going to print this paper he would like to suggest that where he speaks of putting a spectacle lens in the diaphragm in front of the screen, he should define it as a plane lens, because if it were either a convex or a concave lens it would converge or diverge the light. If it were a convex lens it would throw more light on the photometer, or, if concave, it would act the other way. He (the speaker) did not suggest that Mr. Phillips did not lnow that, but it was as well to make it clear. A most interesting point referred to by him was in regard to the limit of quickness of perception-the fact that brightness is more quickly perceived than colour. There was also another point closely connected with that, and he thought it was alluded to later on in the paper-the question of the durability of time that these different senses last on the 
retina. One knew perfectly well that incident light may fall with infinitesimal suddenness on the retina, yet the retina perceives it for a distinct period. That was important, because it would affect the use of the Flicker Photometer, as he understood it, from the description given, because if the rate of the revolutions were too great no flicker at all would be obtained. Light on either surface of the wheel might be different in period, and yet if the period of the revolution of the wheel was quicker than the period of sensibility of the retina to light, there was no flicker. It would be interesting to compare that periodicity with the period of the colour sense, though he did not suppose one could eliminate the light and deal only with the colour. He should be glad if Mr. Phillips could give them an estimate of the amount of light which was absorbed by a plane glass-an uncoloured plane glass as they understood it in ophthalmic work. That would, to a certain extent, affect the percentage of light transmitted by the tinted glasses. $\mathrm{He}$ should also like to know how the thickness of glass affected the amount of light transmitted, that was to say, if No. 3 transmits 50 per cent. with a certain thickness of glass what percentage of light would be transmitted by the same glass of exactly double the thickness?

Dr. Garnet r stated that he would like to ask a question or two. He did not learn the speed at which the cylinder revolves in order to produce the best effect in the Flicker Photometer. He did not know whether it was several revolutions per second or only a very few, and it appeared to him that very much must depend on that. If the cylinder was revolved sufficiently rapidly they would expect to get simply an average sensation whatever might be the illumination of the two sides. If they looked at an ordinary alternating arc light they saw no fliclser whatever-they were not conscious of any variation of the intensity of the light, but if they looked at that light through a wheel which was attached to the alternater which generated the current, as, for example, if the current were being generated by a ring of field magnets rotating within a circle of armatures, and they peeped at the light between the gaps of the field magnets, and if, in addition, they placed their eye in a certain position, they would find that the lamp showed simply as a pair of incandescent carbons, and that the light had 
gone down to a very small percentage of the ordinary illumination. If they moved their eye half the diameter of one of the field magnets, so as to catch the light at the half period, when the current was a maximum, they would see a blaze of electric light, which would appear perfectly steady between the revolving arms. If they examined the arc light with a revolving mirror they would see an effect very similar to what he had described-a great mass of flame, dying down to almost nothing, then becoming a great mass of flame again.

The lamp seemed to be perfectly steady, but the light was going through tremendous fluctuations. If their cylinder was revolved quickly enough they would get an average result, whatever the illumination on each side, and he would like Mr. Phillips to say at what speed the flicker begins when the illumination is not balanced, and then at what speed they were bound to have a flicker when the illumination is balanced in the best way possible. He was a little puzzled over another statement Mr. Phillips made, that the adjustment between the lights was not affected by any peculiarities of the eye. As far as he knew there were no two eyes which saw colours with exactly the same degree of acuteness, that is to say, the colour equation of every two people would be slightly different. The eye of one was mnre acute for the red, that of another more acute far the violet, or the green, as the case might be. If that was so, he could not imagine how it was that two eyes which were looking at a white light in the one case and a red light in the other, while the relative sensibility was different, arrived at exactly the same comparison. He would have expected to find the same inequalities between their adjustments as one finds in the colour equation if they endeavour to match lights with a colour box, or rotating partly-coloured disc. One might go to the extreme case: Would a person who is absolutely colour-blind adjust the instrument at the same balance as a person gifted with ordinary vision? He was very interested in the statement that the eye appreciates more rapidly variations in intensity than it does variations in colour, and he was inclined to wonder if a person were to pass very rapidly along a series of bands of colour, say red and green, what would happen. Would such a person be unconscious of any variation whatever in the light 
which reached him, provided that the intensity of the green were the same as the intensity of the red? It was a very crude way of putting the question, but he thought it struck at the root of the matter-the failure to appreciate rapid variations of colour although rapid variations of intensity could be perceived.

Mr. J. C. Maxiveli Garne'st said there were just two points that occurred to him in listening to Mr. Phillips. The first was as to the difference between the faculty of appreciating brightness and appreciating colour. Sir William Abney, in his book on Colour Vision, states that when a light, of any colour, is diminished beyond a certain amount it is quite impossible to appreciate what colour that light is, that was to say, that if they had a very feeble green light it would look white, and a very feeble red light would also appear white. The second thing in Mr. Phillips's paper to which he wished to call attention, was the question whether the measurements tabulated at the end of the paper had been repeated with different sources of light for the source called "A" by Mr. Phillips. It seemed to him that, for instance, the proportion of light absorbed by a coloured glass would be different according as the source "A" consisted of an incandescent electric light, and of an electric arc. If, for example, it was desired to measure the amount of light absorbed by a glass with a yellow silver stain-a stain which absorbed the blue rays very powerfully, but which absorbed but little red and yellow light -and if, for the purpose of measurement, an incandescent electric light, emitting a rery small proportion of rays of high refrangibility, were used as source " $A$," then the amount of light absorbed by the glass would be but small. If, on the other hand, an electric arc, the light from which is comparatively rich in blue rays, were used as source "A," the amount of light absorbed by the glass would be much larger. It appeared, from this example, that the proportion of light from a given source absorbed by a coloured body must depend on the nature of that source. He would, accordingly, be glad if Mr. Phillips would state whether the numbers to which he had referred had been checked against those obtained with different sources "A."

Dr. Grazebrook said there were one or two points he would like to call attention to. In the first place, he 
thought Mr. Phillips gave the National Physical Laboratory rather too much credit for the method that he described at the Optical Society just about a year ago. The apparatus which he (the Chairman) described in his paper, and which he thought he showed to the meeting. was really the German Konig spectrophotometer. $\mathrm{He}$ thought Mr. Phillips's paper would lead one to suppose it was designed by themselves at the National Physical Laboratory. Of course the advantage of that apparatus for laboratory work over the one shown by $\mathrm{Mr}$. Phillips-and an adrantage which enables it to give an answer to the question put by $\mathrm{Mr}$. Garnett-is that it is a spectrophotometer. Two spectrum colours, and not two white lights, are employed. But he quite agreed in thinking, for the ordinary comparatively rough and ready tests that are wanted, a method more like that described by Mr. Phillips was more likely to be useful; and in connection with that he would like to ask a question (which, perhaps, Mr. Dixey could answer as well as anyone). It was as to whether glasses transmitting 2.5 per cent and $\mathbf{1 . 2}$ per cent. are really wanted for the practical Optician's work. It was a matter that would come up again shortly, in connection with some work of his own, and if Mr. Dixey could answer that question he should be very glad.

Mr. DiXeY interposing, said he could answer more certainly if he could see the glass, but he thought it quite possible that the glass was used practically as a block, and that the same purpose would be served br a bit of vulcanite. He was not quite sure. But it was the custom, though a rare one, to use these very heary glasses.

Dr. GlazeBrook, continuing, said the point, of course, really was, when one came to compare two lights which were in the ratio of 100 to 1 , you were adding somewhat appreciably to the difficulties of measurement. Then, as to a question which $\mathrm{Mr}$. Dixey asked, Mr. Phillips might have an answer, but it happened that they were, at the Laboratory, a few days since, comparing the absorption of two pieces of hard crown and boro silicate crown glass.

He was speaking from memory, but he thought the amount of light lost in both cases was something like 8 to 9 per cent. There was really very little loss by absorption. That led him to another point he wanted to make in connection with the question, there is a loss 
of about 4 per cent. from each of the two reflections that took place at the two places where the light enters and leaves the glass, so that when Mr. Phillips was dealing with the total light transmitted, the light that was lost, it must be remembered, was not all lost by absorption, but part by reflection where the light entered and where it left the lens. Mr. Phillips had a number of questions to answer and they would look forward with pleasure to his replies; but he would take this opportunity of referring to his (the speaker's) own paper about a year ago, and of reporting what progress they had made at the Laboratory with regard to carrying out some of the suggestions made in the Optical Standards Committee's report last April, to which Mr. Phillips referred. Thanks to the kindness of Mr. Aitchison, they hoped to have, quite shortly, a bench which would enable them to make come of the measurements referred to as to tests on binocular glasses, and questions of that kind. Then Mr. Stewart, of Messrs. Ross, Ltd., and Mr. Beck, had combined to equip to a very much better extent than before their apparatus for properly testing photographic lenses; and thanks to the generous anonymous donation given to him some month ago, he had been able to put in hand three benches which would enable him to make quite rapidly all the various tests, including the absorption test, that had been referred to in their discussions during the year. That was due largely to generous gifts from members of the optical trade and other gentlemen. In addition to that he hoped to be authorised next Friday to appoint an assistant, so as to take up this work for Opticians.

Mr. Phillips, in rising to reply, thanked the meeting for the kind way in which they had received his paper. Mr. Dixey had spoken of curvature; of course it should have been mentioned that the glasses tested were plane, but he was making some measurements at present to find the effect of curvature on the photometric results, so that in the near future he would be able to say more on that point. It had been mentioned that beyond a certain speed of wheel no flicker would be observed. This was not quite true, for although the range through which the flicker box could be moved without producing a flicker became greater as speed increased, yet beyond a certain point flicker again appeared. 
[Mr. Dixer here asked what was a suitaible speed for wheel.]

Mr. Phillips replied that a very satisfactory speed was about 300 revolutions per minute. The most sensitive speed, however, varied with the tint of glass tested. $\mathrm{He}$ had not the exact figures to hand at present, as measurements were still being carried out for this determination. It would be well for the flicker box to be fitted with speed regulator marked for difierent colours.

With regard to Dr. Garnett's remarks, he was inclined to think that there was a good deal to be said about the use with the flicker photometer of lamps supplied with alternating current. Undoubtedly there would be some little trouble if the speed of wheel was some multiple of the periodicity of the alternating current supplying the lamps used. One curious fact he had noticed that afternoon was that at a certain speed an image of the lamp filament was discernible on the flicker wheel-the lamps being supplied with alternating current. Dr. Garnett had spoken of visual peculiarities. From the different tests taken it seemed that everyone, independent of visual defects, could use the flicker photometer successfully. All that one had to do was simply to find the point at which the throbbing disappeared. Mention had already been made in the paper to some tests carried out by the designers of the photometer, Messrs. Simmance and $A b a d y$, to determine the effect of visual peculiarity.

In regard to the sense of colour, although colour vision varied with different individuals, it did not affect the use of the photometer, because colour was eliminated. What one saw was simply a disc of greyish-white tint, and the box was mored until it seemed stationary, and flicker disappeared. Mr. Garnett had spoken of the feebleness of the light--whether the intensity had any effect on the results. When working with the photometer, one would not choose too intense a source in order to prevent fatigue of the eye, and if the bench was of a short length the lights need only be of little intensity. In ordinary photometry when using a Lummer-Brodhun, or Bunsen photometer, and dealing with coloured lights, it was the practice to take the readings with almost closed eyes to get rid of the colour as far as possible. This corre- 
sponded to what $\mathrm{Mr}$. Garnett had said with regard to feebleness of the sources of light.

In regard to the sources of light, $A$ and $B$, they had been the same, both being Nernst lamps of the old type. He did not think different sources would affect the result owing to colour being eliminated and only the ratio of brightness compared.

Mr. Garnett, interposing, said he had not meant haring $\mathbf{A}$ and $\mathbf{B}$ different sources, but whether $\mathrm{Mr}$. Phillips had employed different sources for $\mathrm{A}$ in the two tests, the figures for which were given? Had he taken the same measurement with different lights and tabulated two corresponding series of numbers and compared them?

Mr. Phillips replied in the negative, and stated the tests were made with the same source of light at $A$ in both cases. He had reneated the tests to show the reliance in the method and the agreement of the readings. With reference to Dr. Glazebrook's remarks he was pleased to find the trade was so loyally supporting the National Physical Laboratcry, and that they were now so well-equipped for absorption measurements. 